\title{
Information Literacy in CEAB's Accreditation Criteria: The Hidden Attribute
}

\author{
Sharon Murphy \\ Head, Engineering \& Science Library \\ Queen's University \\ murphys@queensu.ca
}

\author{
Nasser Saleh \\ Integrated Learning Librarian \\ Queen's University \\ nasser.saleh@queensu.ca
}

\begin{abstract}
This paper demonstrates how information literacy is a hidden attribute woven throughout CEAB's recent accreditation criteria. The paper focuses in particular on life-long learning and describes how such a model can be developed and transferred in different engineering programs.
\end{abstract}

\section{Introduction}

The Canadian Engineering Accreditation Board (CEAB)'s recent accreditation criteria include twelve graduate attributes. These are: a knowledge base for engineering, problem analysis, investigations, design, use of engineering tools, individual and team work, communication skills, professionalism, impact of engineering on society and the environment, ethics and equity, economics and project management, and finally life-long learning [1]. Life-long learning, the last attribute listed, is defined as the learners' ability to identify and to address their own educational needs in a changing world, sufficiently to maintain their competence and contribute to the advancement of knowledge. Lifelong learning is a major component of information literacy, a commonly used framework for academic librarians to deliver information services and to provide information searching and knowledge management instruction in academic courses.

While the CEAB criteria do not explicitly include information literacy as a graduate attribute, the above strongly suggests that information literacy is an important and essential element of the twelve attributes, each of which can be envisaged as a set of capacities and skills and all of which are interconnected in an information intensive world. Before we discuss the interconnectivity of information literacy and the CEAB attributes, we need to flesh out just what we mean when we use this phrase.

\section{Information Literacy}

Canadian academic libraries conventionally use a framework for understanding, implementing and assessing information literacy that was developed by The Association of College and Research Libraries (ACRL), Science and Technology Section. It describes the information literate engineer as one who demonstrates the following attributes: determines the nature and extent of information needed; acquires needed information effectively and efficiently; evaluates information and its sources critically and incorporates selected information into his or her knowledge base and value system; understands many of the economic, ethical, legal and social issues surrounding the use of information and its technologies and uses information effectively, ethically and legally; and finally, recognizes the need to keep current and understands that information literacy is an important component of lifelong learning [2]. Each of these is further broken into performance indicators or outcome based assessment criteria. The performance indicators are quite granular and some highly specific to science and engineering information skills and abilities. Examples include locating and understanding sources such as standards and patents; as well as keeping oneself up to date using current tools such as RSS feeds.

In practice, academic librarians have been guilty of spending too much time on information finding and emphasizing the mechanics of various databases and technologies when we meet with engineering students. This is a disservice to the power of information literacy and to our students. Rather than conceptualizing information literacy as a linear and discrete set of attributes, it is increasingly understood 
as a critical thinking process which is iterative and profoundly linked to the acquisition and practice of discipline knowledge [3]. Furthermore, it is "constructed through authentic experiences across a range of dimensions which must be developed collectively" [4]. This language is remarkably similar to the language of the recent report, Educating Engineers: Designing for the Future of the Field, which advises that engineering schools adopt more integrative approaches to student learning and describes the "ideal learning trajectory as a spiral with all components revisited at increasing levels of sophistication and interconnections" [5]. The language and practice of both engineering education and information literacy share much in common. So, what does this mean in the Canadian context?

\section{CEAB Attributes and Information Literacy}

The creation, discovery, sharing and practice of engineering skills and knowledge (engineering education) all imply the creation, discovery, sharing, storing and use of engineering information (information literacy). It is the implicit and pervasive nature of the relationship between the two that make information literacy the "hidden attribute". Figure 1 represents the presence of information literacy within and between the attributes.

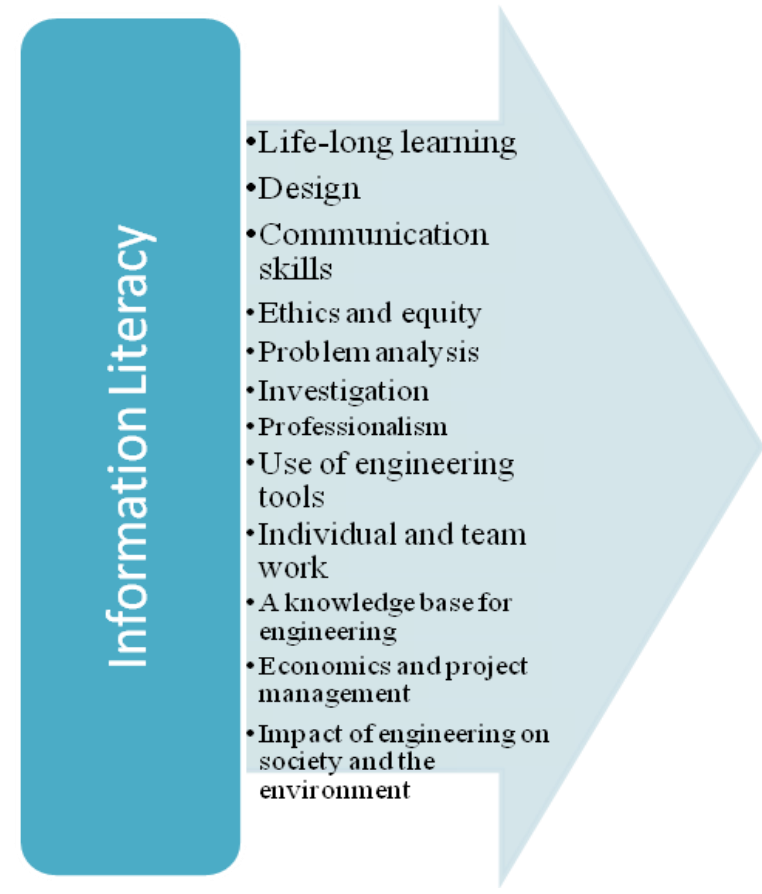

Figure 1: CEAB Attributes and Information Literacy
The descending list and font represent the formal ties we have created at Queen's University between information literacy and each attribute. The ties occur within various courses, with the strongest presence of information literacy in life-long learning, design and communication learning outcomes. Most often information literacy is aligned with life-long learning and there are certainly compelling reasons for this which we elaborate below.

At Queen's we have made significant inroads with both design and communication skills as well.

\section{CEAB defines Design as:}

"an ability to design solutions for complex open-ended engineering problems and to design systems, components or processes that meet specified needs with appropriate attentions to health and safety risks, applicable standards, economic, environmental, cultural and societal considerations." [6]

It is the very open-ended nature of these problems that make them ideal vehicles to learn and practice a variety of information literacy skills. We work with students throughout their undergraduate years on a variety of design projects and courses, culminating with senior design projects. With any open-ended question the first task is to articulate what is known and what needs further data and investigation. This is a primary information literacy skill, the explicit articulation of a problem and the identification of required information. We spend time in the first year design project in APSC 100 on this fundamental skill. Students are encouraged to speak, write and map their problems and resulting information needs. In more senior years students practice their skills at finding and applying appropriate regulations, public policy and standards to their design solutions. We provide class, group, and individual learning tools in these areas. Increasingly we augment our in-person presence with online and Web 2.0 learning tools.

Communication skills comprise reading, writing, speaking and listening. The graduate is expected to do all of this effectively for both technical and nontechnical audiences. [7] Librarians have traditionally provided support on the reading and writing dimension by providing access to materials and citation guidance. These are certainly valid roles, but information literacy demands more. We want the students to perceive themselves as the creators of engineering information; to project to the day when they themselves are writing standards in industry, holding patents and publishing reports. Our students share information and collaborate online habitually. 
This is where we want to meet them and lead them to use a full suite of tools for critical analysis and sharing information. For example, we encourage students to use wiki software for information collaboration. As a result, some design groups contributed to Appropedia (www.appropedia.org), a reference for sustainable development. Students learn research skills while they practice knowledge sharing. They experience that information is both the input and product of their work and that, as they progress through their undergraduate years, both input and product become increasingly sophisticated.

\section{Life Long Learning}

Life-long learning is listed last in CEAB's graduate attributes. Last perhaps because it culminates the others and projects graduates forward into their professional lives. It is demonstrated by:

"An ability to identify and to address their own educational needs in a changing world, sufficiently to maintain their competence and contribute to the advancement of knowledge." [8]

And from the ACRL information literacy standards here are the performance indicators relevant to life-long learning:

1. Recognizes the value of ongoing assimilation and preservation of knowledge in the field.

2. Uses a variety of methods and emerging technologies for keeping current in the field. [8]

The goal in implementing outcome based assessment is to define the criteria or behaviours that demonstrate mastery of the attributes. At Queen's we are currently involved in creating just such a rubric. Here is an example of what it might look like when these attributes are addressed over the course of the undergraduate program. . The performance criteria are emerging in first year, developing in the middle years and established upon graduation.

Table 1: Example of assessment rubric for one indicator of life-long learning attribute.

\begin{tabular}{|l|l|l|l|}
\hline $\begin{array}{l}\text { Criteria/ } \\
\text { Performance } \\
\text { level }\end{array}$ & Emerging & Developing & Established \\
\hline $\begin{array}{l}\text { Identifies } \\
\text { need }\end{array}$ & $\begin{array}{l}\text { Identifies } \\
\text { knowledge } \\
\text { gap }\end{array}$ & $\begin{array}{l}\text { Selects } \\
\text { appropriate } \\
\text { sources }\end{array}$ & $\begin{array}{l}\text { Evaluates } \\
\text { learning and } \\
\text { alternatives }\end{array}$ \\
\hline
\end{tabular}

\section{Conclusion}

Outcome based assessment for the twelve CEAB graduate attributes give form and substance to engineering students learning information literacy during their undergraduate education. Engineering librarians have a significant opportunity to work in partnership with our faculty colleagues within this framework. Let us consider where else information literacy outcomes support the other attributes. Consider project management for example and the critical importance of information management. What software and tools are available? How can the information be preserved through changing technology and company mergers? We should likewise parse through each attribute to explicitly articulate the information literacy components so that they are not hidden. Engineering librarians also need to reconsider information literacy beyond the physical and electronic resources of their library collections and to view information literacy to be more than just the ability to successfully engage with abstracted forms of knowledge. The process of a learner to become information literate is holistic, as it involves the 'whole body' being in and engaging with a range of information and knowledge modalities, which are situated and influenced by the shared experience of learning [9]. The definition of information literacy seemed to be ambiguous for many people including us as librarians and faculty since information landscape, users and patterns have changed dramatically in the last decade. Our approach at Queen's Engineering \& Science library to information literacy in Engineering stems from Lloyd's [10]

\footnotetext{
"Information literate people are engaged, enabled, enriched and embodied by social, procedural and physical information that constitutes an information environment. Information literacy is constituted through the connections that exist between people, artifacts, texts and bodily experiences, which enable individuals to develop both subjective and inter-subjective positions. Information literacy is a way of knowing the many environments that constitute an individual's being in the world"
}

The new CEAB criteria present an opportunity at the course and curriculum level to maximize our students' learning, providing much potential for engineering librarians to be more practically involved in an integrated approach for engineering teaching and learning. 


\section{References}

[1],[6],[7], [8] Engineers Canada, Canadian Accreditation Board, Accreditation Criteria and Procedures. Canadian Council of Professional Engineers, 2008

[2], [8] American College and Research Libraries, Science and Technology Section. Information Literacy

Standards for Science and Technology, 2004:

http://www.ala.org/ala/acrl/acrlstandards/infolitscitech.htm.

[3] S. Markless, "A New Conception of Information Literacy for the Digital Learning Environment in Higher Education", 1 (1), 2009, 25-40.
[4] C. Laverty, "Our Information Literacy heritage: From Evolution to Revolution”, Feliciter, 55 (3), 2009, 88-91.

[5] The Carnegie Foundation for the Advancement of teaching, Educating Engineers: Designing for the Future of the Field, Jossey-Bass, 2008.

[9] A. Lloyd "Information literacy landscapes: An emerging picture", Journal of Documentation, 62(5), 2006, 570-583.

[10] A. Lloyd. "Learning to put out the red stuff: becoming information literate through discursive practice" , Library Quarterly, 77 (2), 2007, 181-198. 